Assessing learning outcomes from experiments in a science competition

This content has been downloaded from IOPscience. Please scroll down to see the full text.

2017 Eur. J. Phys. 38034003

(http://iopscience.iop.org/0143-0807/38/3/034003)

View the table of contents for this issue, or go to the journal homepage for more

Download details:

IP Address: 193.2.73.108

This content was downloaded on 14/02/2017 at 06:45

Please note that terms and conditions apply.

You may also be interested in:

Teaching quantum physics by the sum over paths approach and GeoGebra simulations

$\mathrm{M}$ Malgieri, $\mathrm{P}$ Onorato and $\mathrm{A}$ De Ambrosis

Student evaluation of research projects in a first-year physics laboratory

Manjula D Sharma, Alberto Mendez, Ian M Sefton et al.

An issue encountered in solving problems in electricity and magnetism: curvilinear coordinates

Çalar Gülçiçek and Volkan Daml

Filling or draining a water bottle with two holes

Rod Cross

Wind or water turbine power augmentation using the system of guiding surfaces

V P Bashurin, I N Budnikov, V Yu Hatunkin et al.

The German Physics Olympiad-identifying and inspiring talents

$S$ Petersen and $P$ Wulff

Numerical analysis of the texture effect on the hydrodynamic performance of a mechanical seal

M Adjemout, N Brunetiere and J Bouyer

Max 2-SAT with up to 108 qubits

Siddhartha Santra, Gregory Quiroz, Greg Ver Steeg et al.

Present-day school physics syllabuses

J R Crellin, R J J Orton and D A Tawney 


\title{
Assessing learning outcomes from experiments in a science competition
}

\author{
Barbara Rovšek \\ Slovenia \\ E-mail: barbara.rovsek@pef.uni-lj.si \\ Received 16 September 2016, revised 30 November 2016 \\ Accepted for publication 22 December 2016 \\ Published 8 February 2017
}

Faculty of Education, University of Ljubljana, Kardeljeva ploščad 16, 1000 Ljubljana,

\begin{abstract}
The Slovene Science competition for primary school students aged between 6 and 12 years will be explained briefly. The competition is based on experiments, which should be done well in advance either at school or at home. An example of the proposed experiment for 11 and 12 year old students from the past year-a syphon—will be presented as well as the assessment questions referring to this particular experiment, which were posed at the competition. A fair proportion of the population took part in the competition. We will present a brief analysis of the obtained data, which offers an insight into the difficulty level of the questions.
\end{abstract}

Keywords: competition, assessment, experiments, science

(Some figures may appear in colour only in the online journal)

\section{Introduction: the competition}

We ran the second competition in science for 6 to 12 year old students in Slovenia in the school year 2015/2016, while the third season is taking place during the school year 2016/ 2017. The competition is organised by The Society of Mathematicians, Physicists and Astronomers of Slovenia (DMFA Slovenije) [1]. The members of the competition committee are university lecturers, and middle school and primary school teachers working in three major science disciplines; physics, biology, and chemistry.

All questions in the competition are based on science experiments and observations, which should be done prior to the competition, either at school or at home. The experiments are proposed by the members of the competition committee, who also develop all the questions for the competition. The idea for performing the experiments well in advance came from the Polish science competition Świetlik [2]. For each age group, three science 

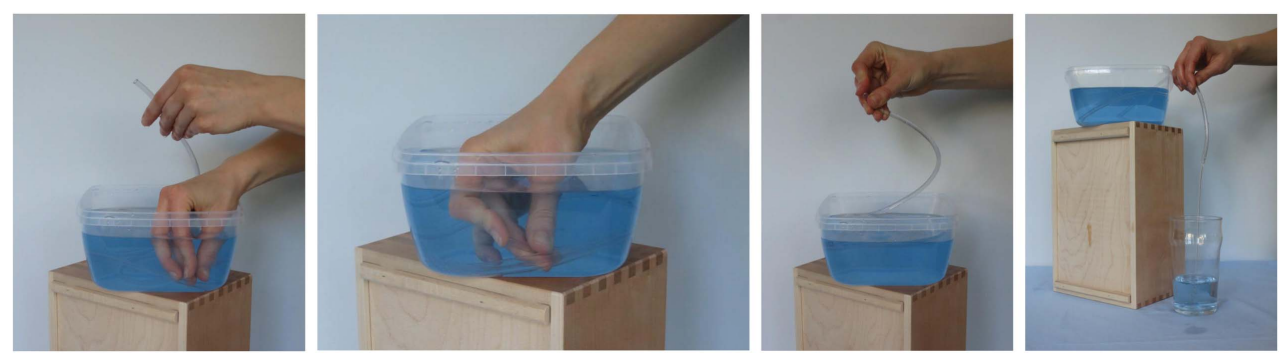

Figure 1. A photographed sequence of steps from (a) to (d) showing what to do to get rid of air bubbles in the tube and to enable the water flow in the first part of the syphon experiment.

experiments are proposed in the beginning of the school year [3], and students should perform them sometime before the competition. The competition takes place in the middle of the school year. Students participate individually. There were more than 9000 participants from half of the Slovene primary schools in the first run [4] and the next year the number of participants grew to more than 15000 . Participation in the competition is voluntary. The competition would not be possible without the help of teachers from all the participating schools. Frequently, the teachers organise experimentation in the schools prior to the competition, they run the competition and after the competition they enter the answers of their students into our web-based computer system.

Our motivation for organising the competition can be summarised with the general statement: not learning about science, but doing it. By doing science, we actually mean using (and meanwhile developing and improving) skills and abilities, which are the content of the scientific method and include activities such as performing observations and experiments, recognising patterns in observed phenomena, detecting and testing the underlying rules (formulating and testing simple hypotheses) [5-8]. Introducing the proposed activities in the format of a competition, we are faced with some contradictory objectives. On the one hand, our aim is to popularise science and experimentation. Therefore, we would like to reach as many students (and teachers) as possible and at the end leave most of them at least fairly satisfied with the process and its outcomes. On the other hand, it is a competition and the objective of a competition in general is to find the most talented, able and interested students. We try to maintain a balance between both needs through paying attention to the choice of experiments and to the design of the competition questions. For example, to a certain extent, the experiments should have surprising outcomes and should be performed with simple and available resources. During the competition, most of the questions should present a bit of a challenge to the majority of the participants, while they should be able to solve most of them. However, we also need some more difficult questions, which help us to identify the most gifted students.

One of last year's (school year 2015/2016) experiments for the oldest participating students was a syphon. The most difficult questions (to challenge the gifted students) in the competition turned out to be the ones that asked about the outcomes of the syphon experiment in a variety of vessel settings. The syphon experiment set will be described, the competition questions related to this particular experiment will be given, and the results of about $10 \%$ of the whole generation that participated in the competition will be briefly analysed. 


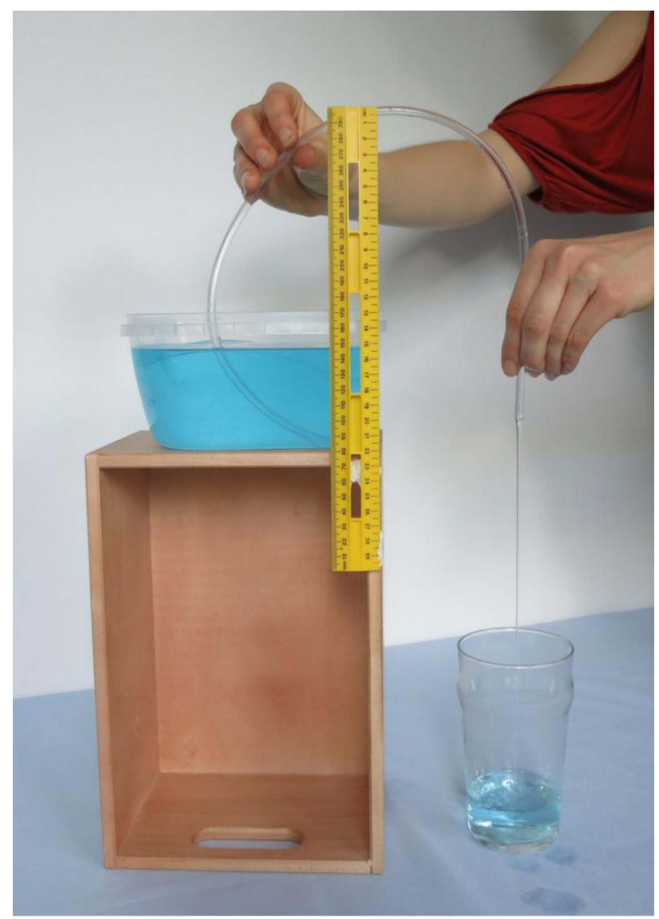

Figure 2. The first observation/measurement that should be performed.

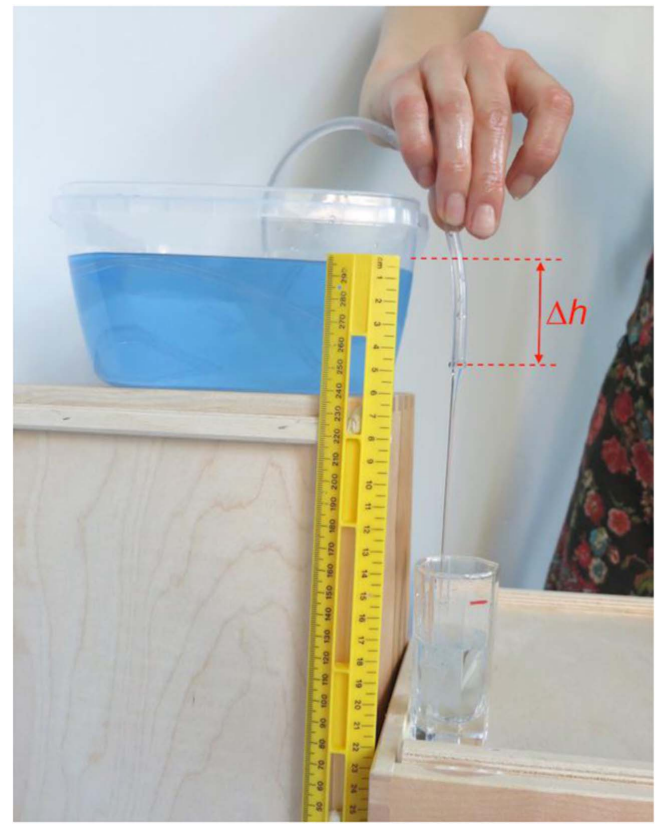

Figure 3. A photo showing the most important measurement within the syphon experiment. 


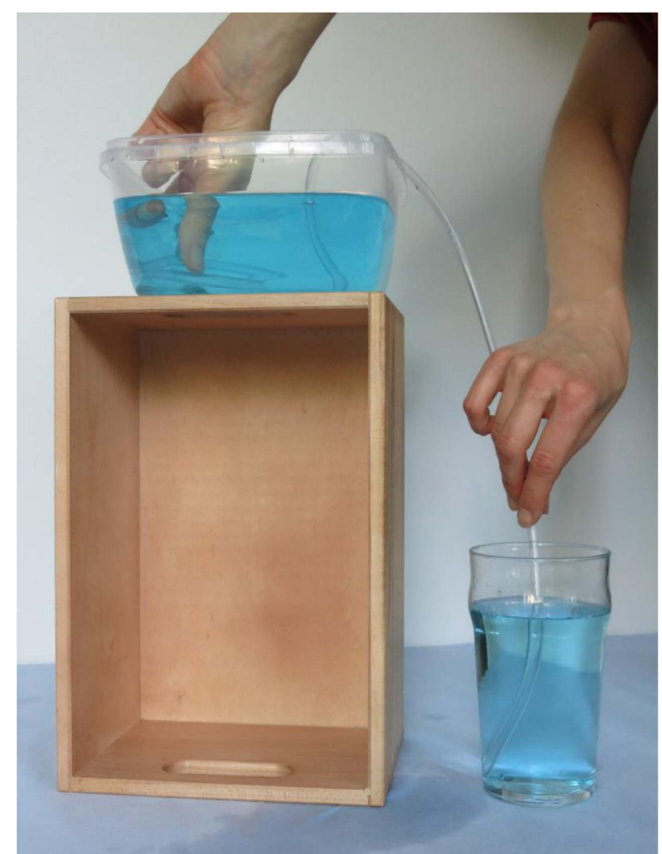

Figure 4. A photo showing the variation of the experiment where the other end of the tube is submerged under the water.

\section{The experiment}

All proposals for the experiments are written in the same fashion. In the first part of the proposal, the basic variation of the experiment is explained and the procedure (what and how to do) is given in detail both in words and with an illustrated (photographed) sequence. Next, some additional variations of the experiment are suggested. The proposal ends with questions that pay attention to particular aspects of the observed phenomenon. With part of the questions we want to induce the establishment of a broader picture of the phenomenon and guide students to find connections with real-life phenomena, not obviously related to the abstract and elementary experiment given at the beginning of the proposal.

There are no tables given to help the students to organise their data. They are supposed to deduce for themselves how they will write down their observations, measurements, and conclusions.

The basic variation of the syphon experiment was proposed with photographs (figures 13 ) and short descriptions in six steps. To begin with, one should be able to initiate the water flow through a tube. Figures 1(a)-(c) show how the tube should be filled with water without air bubbles to enable the water flow through a tube from a vessel above to a glass below. The complete tube should be submerged under the water surface and filled with water. The end of the tube where the water flows in stays in the vessel and under the water surface all the time. The end of the tube where the water flows out should be blocked when taken out of the water, as shown in figure 1(c) and reopened when this end is far below the level of the vessel, see figure $1(\mathrm{~d})$.

Figure 2 shows the first observation/measurement that should have been made: the students were instructed to find out how high above the water surface in the vessel the tube 
could span but still ensure the water flow. The objectives of this step were to become familiar with the strange phenomenon of water running uphill and also the recognition of the parameters which influence the water flow. We assumed the students would have some difficulties in performing this part of the experiment. Only one variable at a time should be changed in order to recognise its influence on the water flow. While the students were striving to keep everything but the maximum height of the tube the same, they could, had they been careful enough, also discover other important dependencies and sometimes surprising independencies. We deliberately did not give direct instructions on how to check them.

Figure 3 shows the main measurement which should have been performed. The students were instructed to observe how the difference $\Delta h$ in height of the water surface in the vessel and the end of the tube where the water flows out influence the water flow. The end of the tube where the water flows in had to remain at the same position (at the bottom of the vessel). The students had to measure the time in which a small glass is filled with water in dependence of $\Delta h$. They had to fill the glass with the water from the vessel while keeping the height of the other end of the tube constant. The glass was small, the height of the water level in the vessel hardly changed during the filling of the glass and, therefore, $\Delta h$ also did not change considerably. They had to repeat the measurement of time at different $\Delta h$.

The objective was to recognise that the end of the tube where the water flows out should be below the level of the water surface in the vessel. Moreover, the larger the difference in height, the larger the water flux through the tube.

In the second part of the instructions there were suggestions for variations of the experiment, for example, observing the flow through the tube with both its ends being in the water, see figure 4 . Some of the questions at the end of the proposal which were given to guide the experimenters were concrete, for example, Which conditions must be fulfilled so that the water can flow out from the vessel through the tube? How high must the end of the tube be where the water flows into the tube? Is it possible to empty the vessel completely?

\section{Objectives of experimentation}

The water flow between two vessels through a tube is a topic scheduled for physics lessons on elementary Bernoulli hydrodynamics only in high school. We are aware of the difficulty of the subject matter itself, knowing that the ideas of the key role mechanisms that make syphons work remain a bit controversial even in the 21 st century: authors in numerous recent papers discuss to what extent the atmospheric pressure, gravity, and intermolecular attracting forces influence the phenomenon of fluid running uphill through a tube [9-12].

Therefore, we acknowledge the need for appropriate teaching transformations of the subject matter, where students' preconceptions and learning difficulties are taken into account. Students rely on their intuitive ideas and, for example, often ignore the influence of atmospheric pressure on fluid flow in various devices from straws to syringes and sometimes do not use the concept of pressure to understand the fluid flow at all. In [13] an analysis of the 'explanations' of syphon principles from common textbooks on physics courses for undergraduates and the development of a general and not content-specific explanatory principle are given as an example of the development of the pedagogical content knowledge [14, 15].

We had no intention whatsoever to give or provoke a full quantitative explanation of the syphon. Nevertheless, we think there are no obstacles preventing younger students from observing and detecting patterns in a phenomenon and recognising correlations and semiquantitative underlying connections between observables. This is in general the first step in any scientific procedure and recognised as important also in learning [5-8]. 
The ultimate objective of the experiment was to recognise the conditions which enable the water flow between two vessels through a tube. To ensure there are no air bubbles in the tube, there are three general (almost) independent conditions, which all have to be met to enable the water flow through a tube between two vessels and which also define the final water levels in a variety of different vessel settings. These are:

$\mathrm{C} 1$. The end of the tube where the water flows into the tube should obviously be below the water surface in the first vessel.

$\mathrm{C} 2$. The other end of the tube where the water flows out from the tube to the second vessel (the glass) should ALSO be below the water surface in the FIRST vessel.

C3. The water can only flow from the first vessel to the second if the water surface in the first vessel is above the water surface in the second.

The first condition $\mathrm{C} 1$ is rather obvious even to someone who did not perform the experiment. The third condition $\mathrm{C} 3$ in its form is less straightforward albeit connected to obvious observation of water flowing downhill. The second condition $\mathrm{C} 2$ is far from obvious and should have been the most important discovery of the experimentation. (In fact, $\mathrm{C} 2$ could be derived from $\mathrm{C} 3$ using symmetry considerations and reductio ad absurdum; if the condition $\mathrm{C} 2$ is not necessary, we can easily imagine a situation where the water flow and water levels would be in conflict with condition C3.)

Following the guidelines for experimentation, two findings were implied in addition to the three discrete conditions (the water either flows or does not flow), and these are:

F1. The other end of the tube where the water flows out can be submerged under the water surface in the second vessel (conditions C1, C2, and C3 apply the same).

F2 . The water flux depends on the difference in height: if the other end of the tube is above the water surface in the second vessel, the altitudes which matter are the altitudes of the water surface in the first vessel and the altitude of the other end of the tube, and if the other end is submerged below the water surface in the second vessel, the altitudes which matter are the altitudes of the water surface in both vessels. The larger the difference in altitude, the stronger the water flux. The guidelines for experimentation (see figure 3) were pointing precisely to the discovery of this particular dependence.

\section{Questions at the competition}

There is always a substantial challenge associated with the design of assessment questions. Even more so when the questions should allow for an assessment of the learning outcomes of the experimentation, to allow us to clearly identify those who did and those who did not perform the experiments with enough care. The measured success of an individual at solving the questions should be monotonically and positively correlated to her or his abilities, efforts, and success at implementation of the scientific method in her or his own experimentation. The aim is to compose several tasks of different types and varying complexity, with not too many correct solutions obvious to someone who did not perform the experiments.

Four questions in the test were related to the syphon experiment. The maximum total score for the complete test was 47 points and 21 of them could be earned from the syphon questions. Question Q1 was a set of open-ended questions, questions Q2 and Q3 were double multiple choice questions and question Q4 was a set of polar yes or no questions. In the following, questions $\mathrm{Q} 1-\mathrm{Q} 4$ are given together with the correct answers $(C A)$. 

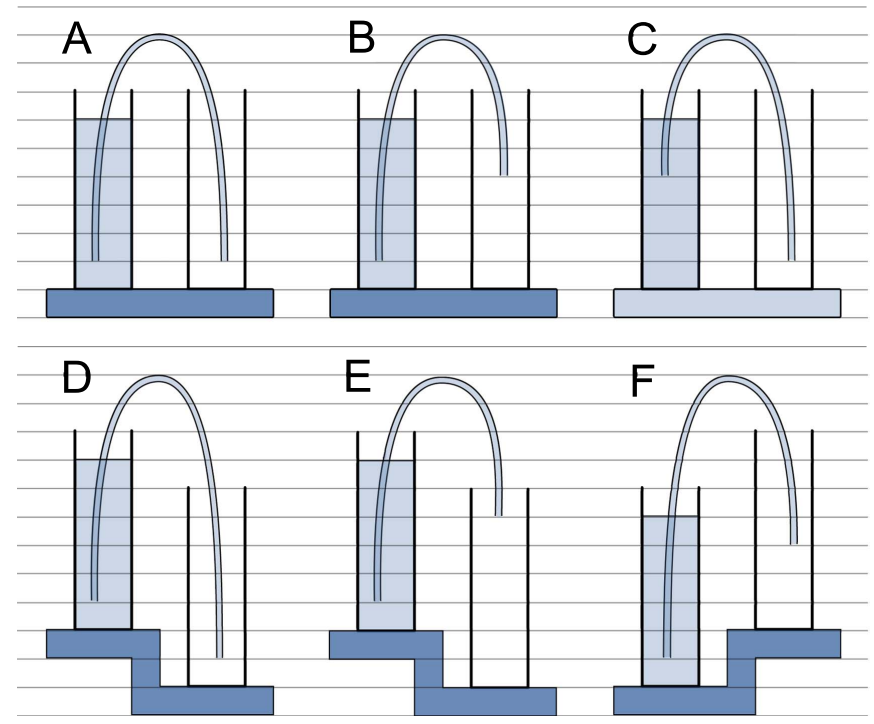

Figure 5. Question Q1.
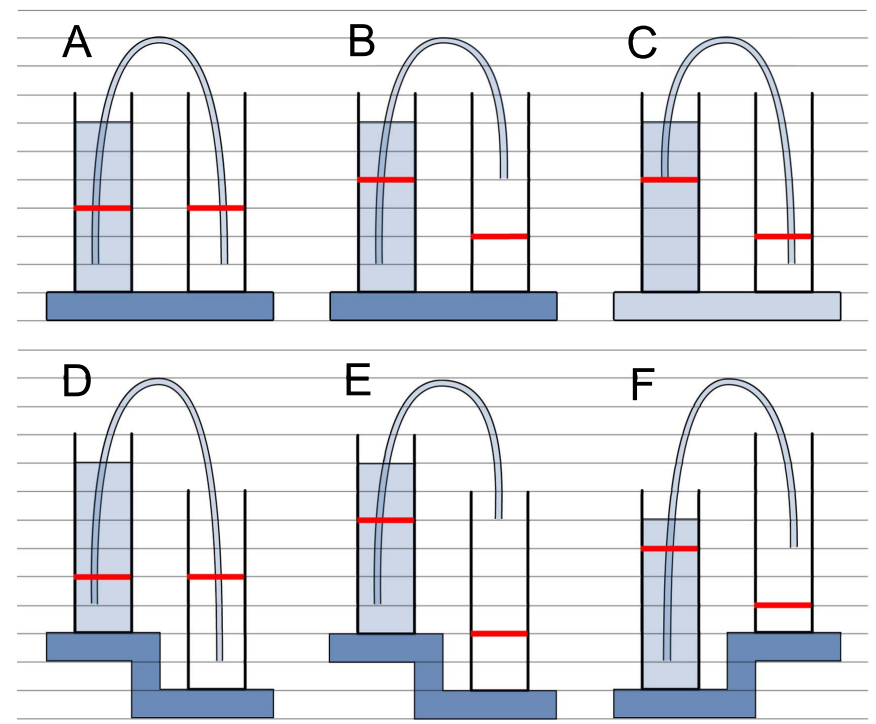

Figure 6. Final water levels in vessels for different placements of vessels and a tube.

Q1. The water is flowing through a tube between two cylindrical vessels of equal size. In the beginning, the first vessel is full and the second is empty. For each placement of the vessels and a tube (stationary during the water flow) shown in figure 5 (cases from AF) draw horizontal lines on the vessels, denoting the water level in both vessels when the water flow stops.

(The correct answer to Q1 is shown in figure 6.) 


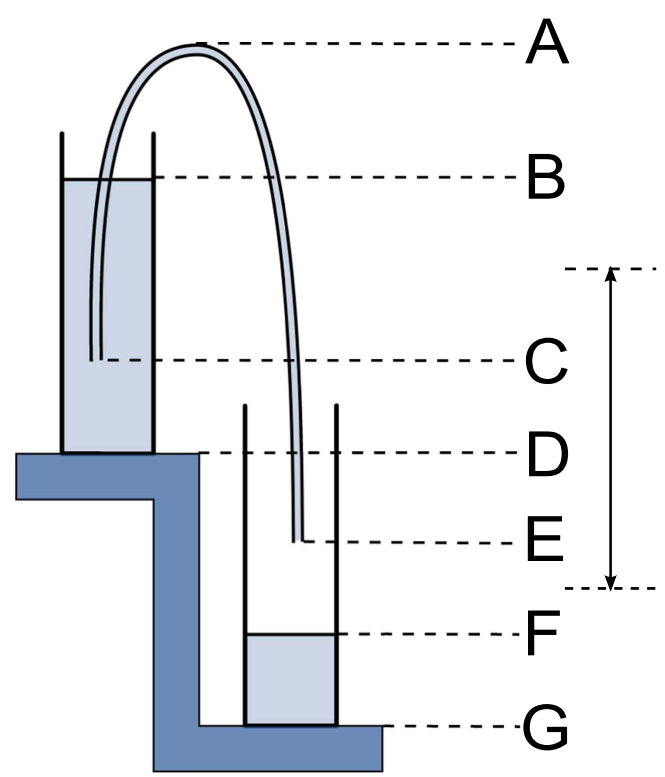

Figure 7. Question Q2.

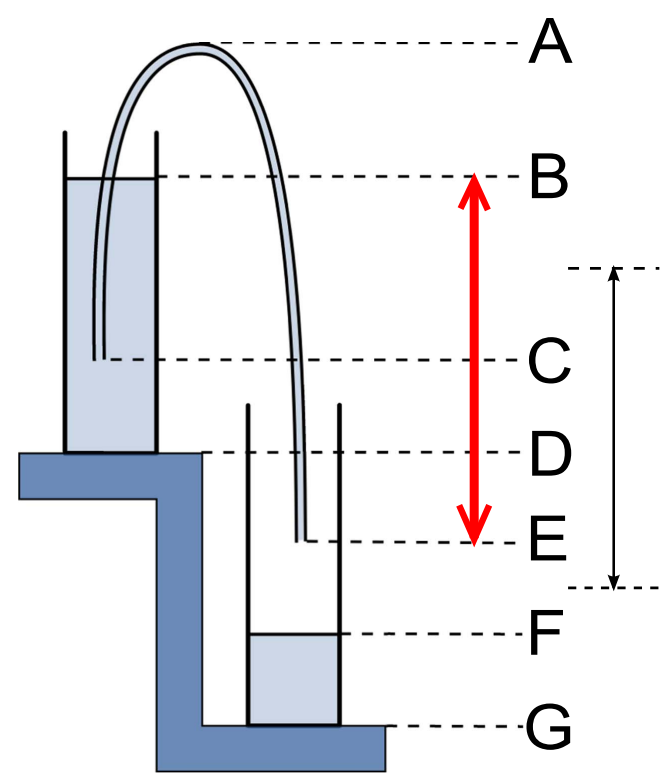

Figure 8. The correct answer to Q2.

Q2. Which height difference (between heights from $A-G$, see figure 7) influences the instantaneous velocity of the water flowing through a tube between the two vessels the most? Draw an arrow between these two heights, as shown in the figure.

(The correct answer to Q2 is shown in figure 8.) 

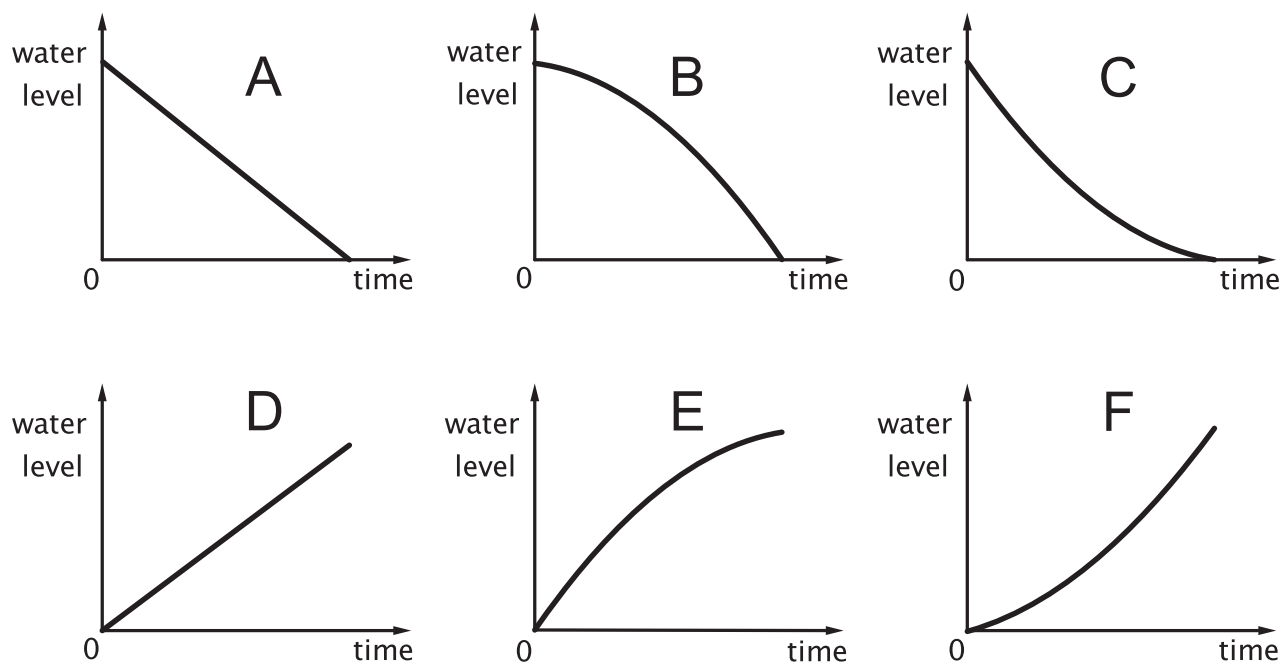

Figure 9. Question Q3.

Q3. The water flows through a tube between two cylindrical vessels of equal size. In the beginning, the first vessel is full and the second is empty, while at the end the opposite is true. The placement of the vessels and the tube is stationary. Write down the answers.

(a) Which graph (in figure 9) correctly shows how the water level is changing with time in the vessel from which the water flows OUT? $(C A: \mathrm{C})$

(b) Which graph (in figure 9) correctly shows how the water level is changing with time in the vessel to which the water flows IN? $(C A: \mathrm{E})$

Q4. Which conditions, written below, MUST be fulfilled if the water flows through a tube from the first vessel to the second? Encircle YES, if the condition is necessary, and NO, if not.

(a) The end of the tube in the first vessel is below the water surface in the first vessel. (CA: YES)

(b) The other end of the tube in the second vessel is below the water surface in the second vessel. ( $C A: \mathrm{NO}$ )

(c) The other end of the tube is above the water surface in the second vessel. (CA: NO)

(d) There is more water in the first vessel than in the second. (CA: NO)

(e) The other end of the tube is lower than the end of the tube in the first vessel. (CA: NO)

(f) The bottom of the first vessel is higher than the bottom of the second vessel. (CA: NO)

(g) The water surface in the first vessel is at larger altitude than the water surface in the second vessel. (CA: YES)

Keeping in mind the three conditions C1, C2, and C3, questions Q1 and Q4 and can be solved. In each vessel setting in Q1, the water flow stops when the first of them ceases. Condition $\mathrm{C} 1$ ceases in setting $\mathrm{C}$, condition $\mathrm{C} 3$ ceases in settings $\mathrm{A}$ and $\mathrm{D}$ and the most subtle condition $\mathrm{C} 2$ ceases in settings $\mathrm{B}, \mathrm{E}$, and $\mathrm{F}$. The proportion of students who answered the subquestions of Q1 correctly is in agreement with the complexity of the conditions $\mathrm{C} 1, \mathrm{C} 2$, 


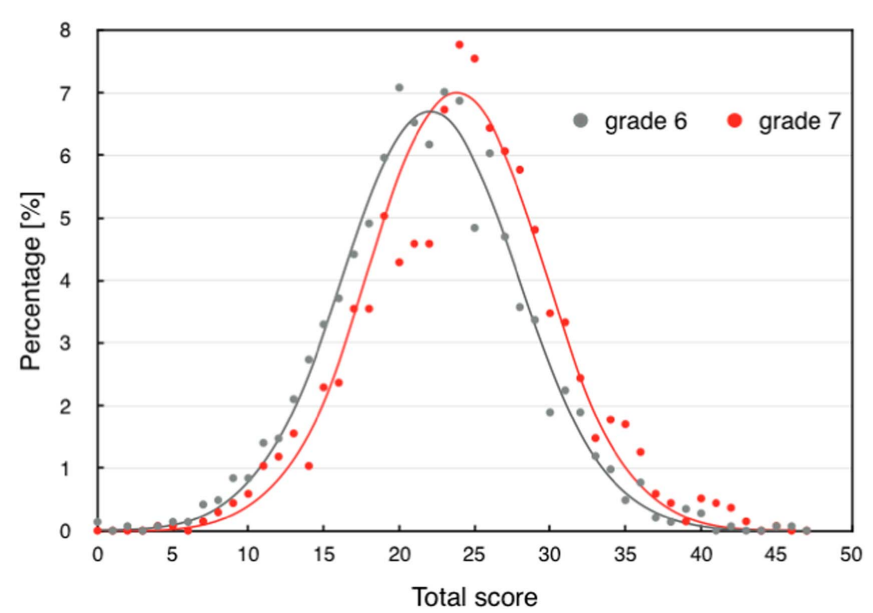

Figure 10. Total score distributions.

Table 1. Proportion of students with correct answers to question Q1.

\begin{tabular}{lcc}
\hline Setting & 6th grade $(\%)$ & 7th grade $(\%)$ \\
\hline A & 31.7 & 33.3 \\
B & 11.2 & 13.5 \\
C & 28.9 & 37.7 \\
D & 19.2 & 21.6 \\
E & 8.6 & 12.7 \\
F & 10.4 & 14.1 \\
\hline N & 1426 & 1352 \\
\hline
\end{tabular}

and C3, as will be presented in the following section. The task in question Q4 was to identify precisely two of the three necessary conditions among seven suggestions.

Question Q2 asked about finding F2 (following directly from experimentation) and in the more complex question Q3 the same finding was addressed indirectly and comprehension of the graphical representation of the phenomenon was also questioned.

\section{Results}

It is beyond the scope of this paper to present a detailed analysis of all the results. Only an example of data analysis will be presented, giving partial information about the difficulty of some of the questions, the quality of the distractors and differentiating potential of some questions.

The overall results of the 6th and 7th graders are presented in histograms in figure 10. The older students did slightly better; the mean total score of the 6th graders was 22(.0) points and the mean total score of 7th graders was 24(.2) with $\sigma$ in both groups being approximately 6 .

As the data gathered at the competition shows, the problems related to the syphon experiment (among the three proposed experiments) were the most difficult. 
Table 2. Proportion of students with the number of correct partial answers (and overall points) to question Q1.

\begin{tabular}{lcc}
\hline Overall points & 6th grade $(\%)$ & 7th grade $(\%)$ \\
\hline 0 & 50.5 & 44.4 \\
1 & 18.0 & 17.6 \\
2 & 13.9 & 15.1 \\
3 & 10.5 & 13.8 \\
4 & 4.5 & 4.4 \\
5 & 1.2 & 2.3 \\
6 & 1.5 & 2.4 \\
\hline
\end{tabular}

Table 3. Proportion of students who chose different answers to question Q2.

\begin{tabular}{lrrrrr}
\hline & \multicolumn{2}{c}{ 6th grade (\%) } & & \multicolumn{2}{c}{ 7th grade (\%) } \\
\cline { 2 - 3 } \cline { 6 - 6 } Levels & higher & lower & & higher & lower \\
\hline $\mathrm{A}$ & 27.4 & 0.3 & & 31.4 & 0.1 \\
$\mathrm{~B}$ & $\mathbf{3 1 . 9}$ & 6.3 & & $\mathbf{3 3 . 3}$ & 6.4 \\
$\mathrm{C}$ & 24.7 & 12.9 & & 23.1 & 12.8 \\
$\mathrm{D}$ & 10.5 & 12.6 & & 10.0 & 15.8 \\
$\mathrm{E}$ & 3.1 & $\mathbf{3 1 . 9}$ & & 1.4 & $\mathbf{3 2 . 4}$ \\
$\mathrm{F}$ & 1.9 & 14.0 & & 0.6 & 12.2 \\
$\mathrm{G}$ & 0.4 & 22.0 & & 0.2 & 20.3 \\
\hline $\mathrm{N}$ & 1144 & 1132 & & 1118 & 1126 \\
\hline
\end{tabular}

There were 2778 students who solved (open) question Q1. Table 1 shows the frequency of correct answers for different vessel settings. Setting A was the simplest and basic, but still only one third of the students were able to draw the water levels correctly. One out of 10 students (in 6th grade) and one out of 7 students (in 7th grade) was also able to draw the water levels correctly in the three settings B, E, and F, which were questioning the most non-trivial conclusion $\mathrm{C} 2$. The maximum points for $\mathrm{Q} 1$ were 6. Table 2 shows the distribution of the score for Q1. Obviously, question Q1 was difficult indeed.

In table 3, the frequency of partial answers to question Q2 are shown. A student drew an arrow between the two levels among the levels from A-G. The higher level was taken as the first part of the answer and the lower level was taken as the second part of the answer. The correct partial answers are given in bold. Approximately one third of the students chose the correct partial answers B for the higher level and E for the lower level and $9.3 \%$ of students correctly chose both levels. The most frequently chosen combination of both partial answers was C (higher)-E (lower), which was chosen by $12.4 \%$ of students.

Table 3 points to some negligible unreliability of the data. There were probably some mistakes in transcriptions from students' papers to the computer database: most obviously level A cannot be the lower level and level $G$ cannot be the higher level, see figure 8 (the other possible explanation of the data inconsistency could be inadequate literacy or sloppiness of the student confusing the top and the bottom).

Apart from the difficulty of the questions and the effectiveness of distractors (wrong possible choices of multiple choice questions, shown for example in table 3 for question Q2) the item response curve (IRC) analysis can be done on the given questions [16, 17]. The 


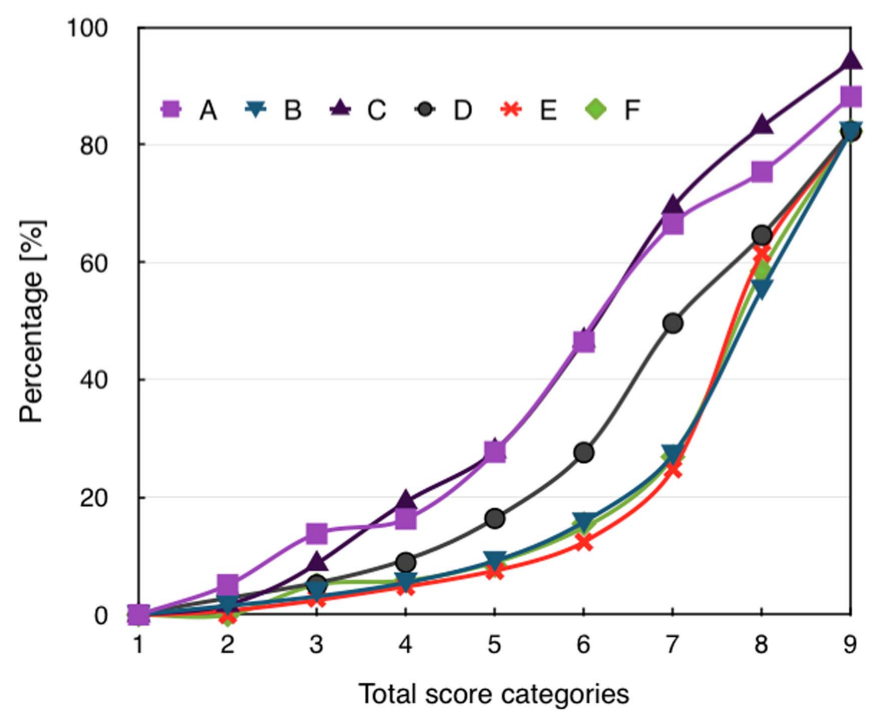

Figure 11. IRC for question Q1. Percentage of students drawing correctly the final water levels in different vessel settings from A-F is shown in correlation with the sum of the points which the students achieved in the competition.

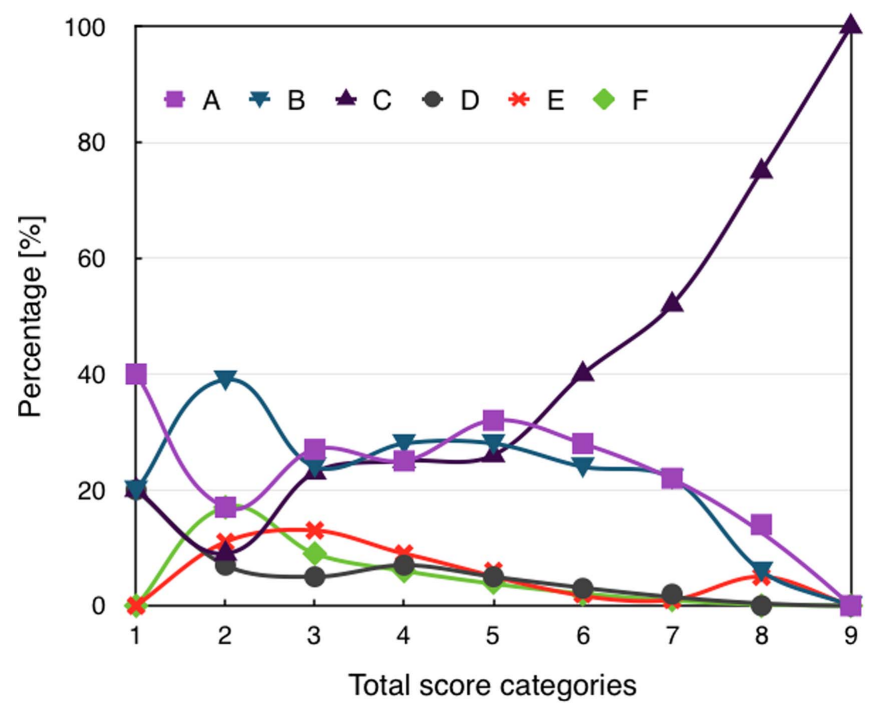

Figure 12. IRC for question Q3a shows the percentages of students who have chosen various possible graphs from $\mathrm{A}-\mathrm{F}$ as answers to question $\mathrm{Q} 3 \mathrm{a}$. The correct answer was $\mathrm{C}$.

results of the IRC give a deeper insight into the quality of the questions, as well as into the abilities of the participating students. As an example, IRC analysis was performed on two questions, Q1 and Q3a, and the curves are shown in figures 11 and 12. We assume that the students' ability levels correlate with their total score. The maximum total score for the test was 47 points. For better statistics, nine equidistant categories of the total score were formed, 
Table 4. Total score of individual participants falls into one of nine equidistant total score categories. The table shows the numbers of participants $N$ within the total score categories.

\begin{tabular}{lrr}
\hline Total score & Category & \multicolumn{1}{c}{$N$} \\
\hline $0-5$ & 1 & 5 \\
$6-10$ & 2 & 46 \\
$11-15$ & 3 & 240 \\
$16-20$ & 4 & 608 \\
$21-25$ & 5 & 856 \\
$26-30$ & 6 & 628 \\
$31-35$ & 7 & 241 \\
$36-40$ & 8 & 65 \\
$41-47$ & 9 & 17 \\
\hline $0-47$ & all & 2778 \\
\hline
\end{tabular}

as given in table 4 . As can be seen in figure 11, the three vessel settings testing the non-trivial conclusion $\mathrm{C} 2$ (B, E, F) efficiently differentiate the students with the highest abilities (in total score categories 8 and 9) from the others, showing a rapid rise from category 7 to category 8 . It has to be stressed that the aim of the competition is to differentiate the students with the highest abilities from the rest; we want to have a clear picture at the top; we do not seek primarily to find the differences in the middle (we nevertheless get some information about the middle as well).

The last example of the data analysis refers to question Q3a and shows the percentage of students who chose a particular graph as the one showing how the height of the water surface changes with time during the outflow of the water. Most of the students in the top total score categories paid attention to the initial state (vessel was full in the beginning, and the water level lowers with time when the water flows out of the vessel, as given in graphs A, B, and C). Again, we have a rapid rise between categories 5 and 6 for the correct answer $\mathrm{C}$.

\section{Conclusions}

Due to various reasons, the new science competition immediately found acceptance in most of the Slovene primary schools. We are satisfied, because the students and teachers like it. We see this competition primarily as a tool for triggering and promoting experimentation of students at science lessons, to steer them towards using and internalising scientific procedures and reasoning. To teachers, we provide materials - ideas for experiments and instruments for the assessment of knowledge and understanding, obtained through experimentation. The teachers of the youngest students are generally not experts in science and our guidance is especially important and valuable to them. We are convinced that we provide a service by teaching the teachers as well-and they recognise and appreciate that. Due to the immediate impact we have had on teaching, we also feel responsible for maintaining the established standards in the future.

\section{Acknowledgements}

The competition on such a scale would not have been possible without cooperation. The author wishes to thank all the teachers from the Slovene primary schools for taking part in the 
competition, and colleagues from the competition committee Jurij Bajc, Andrej Guštin, Dušan Krnel, Luka Praprotnik, Gregor Torkar, and Sašo Žigon for their contribution in designing the experiments and for fruitful discussions about competition questions. The author also wishes to acknowledge the web-based ICT support from DMFA Slovenije.

\section{References}

[1] Web pages of the Society: http://dmfa.si/Default.aspx

[2] Sokolowska D 2010 Physics Community and Cooperation: Selected Contributions from the GIREP-EPEC \& PHES 2009 International Conference (Leicester: Lulu, The Centre for Interdisciplinary Science) p 352

[3] The call of the competition can be found on the web page https://dmfa.si/Tekmovanja/NaOS/ Razpis.aspx and on the web page https://kresnickadmfa.si

[4] Rovšek B 2016 Phys. Teach. 54223

[5] Etkina E, Van Heuvelen A, Brookes D T and Mills D 2002 Phys. Teach. 40351

[6] Gibson H L and Chase C 2002 Sci. Educ. 86693

[7] Hmelo-Silver C E, Duncan R G, Clark A and Chinn C A 2007 Educ. Psychol. 4299

[8] Minner D D, Levy A J and Century J 2010 J. Res. Sci. Teach. 47474

[9] Hughes S W and Gurung S 2014 Sci. Rep. 44741

[10] Boatwright A L, Puttick S and Licence P 2011 J. Chem. Educ. 881547

[11] Hughes S W 2011 Phys. Educ. 46298

[12] Ramette J J and Ramette R W 2011 Phys. Educ. 46412

[13] de Berg K C and Greive C E 1999 Aust. Sci. Teach. J. 4519

[14] van Driel J H, Verloop N and de Vos W 1998 J. Res. Sci. Teach. 35673

[15] Shulman L S 1986 Educ. Res. 154

[16] Lord F M 1980 Applications of Item Response Theory to Practical Testing Problems (Mahwah, NJ: Erlbaum)

[17] Morris G A, Branum-Martin L, Harshman N, Baker S D, Mazur E, Dutta S, Mzoughi T and McCaulay V 2006 Am. J. Phys. 74449 